\title{
Increasing nitrogen limitation in the Bothnian Sea, potentially caused by inflow of phosphate-rich water from the Baltic Proper
}

\author{
Carl Rolff, Tina Elfwing
}

Received: 15 October 2014/Revised: 24 February 2015/Accepted: 29 April 2015/Published online: 20 May 2015

\begin{abstract}
The study showed that the open water of the Bothnian Sea (BS) is likely to have shifted from altering nitrogen and phosphorous limitations of the spring bloom to more nitrogen-limited conditions during the last 20 years. This is affected by the by inflow of phosphaterich and oxygen-depleted water from depths near the halocline in the northern Baltic Proper, where severe oxygen conditions currently cause extreme phosphate concentrations in the deep water. The change in relation between inorganic nitrogen and phosphorous in the BS occurs first in the deep water and then progresses to the surface water. The change can potentially cause increased production in the $\mathrm{BS}$ and more frequent cyanobacterial blooms. There does not appear to be any immediate concern in the short-term perspective for the state of the $\mathrm{BS}$, but a progression of the processes may lead to a more eutrophic state of the BS.
\end{abstract}

Keywords Bothnian Sea - Baltic - Nutrient limitation · Redfield · Eutrophication - Cyanobacteria

\section{INTRODUCTION}

The purpose of this study was to investigate if the spring bloom in the Gulf of Bothnia (GoB, the northernmost part of the Baltic Sea) is potentially limited by nitrogen or phosphorous and if this regulation is changing. The highlevel nitrogen treatment prescribed by EU directive (91/ $271 / \mathrm{EEC}$ ) has not been required in the GoB because production in this water body has been considered generally

Electronic supplementary material The online version of this article (doi:10.1007/s13280-015-0675-3) contains supplementary material, which is available to authorized users. phosphorous limited, whereas the Baltic Proper is nitrogen limited (Supplementary Material, Fig. S1). The export of nitrogen from the GoB to the nitrogen-sensitive Baltic Proper has also been estimated to be comparatively small (Savchuk 2005). Recurrent cyanobacterial blooms in the southern part of the GoB (e.g., Jaanus et al. 2011), however, suggest that the production regulation has changed. This study tests the hypothesis that the relation between inorganic nitrogen and phosphorous in winter nutrients of surface water has shifted toward more nitrogen-limited conditions, assuming the Redfield ratio to be optimal for phytoplankton growth.

The GoB is a large fjord-like, estuarine, nontidal water body. It is in the west, north and east enclosed by Sweden and Finland. The surface salinity decreases from 5 to 6 PSU in the south to 2 PSU in the north. It consists of two major basins separated by a sill: the northern Bothnian Bay (BB) and the southern Bothnian Sea (BS) (Fig. 1). The BB and BS, respectively, have volumes of 1481 and $4308 \mathrm{~km}^{3}$ and mean depths of 41 and $66 \mathrm{~m}$ (Leppäranta and Myrberg 2009). The residence time of water in the GoB is short and has for the BS recently been estimated to 4 years (Yi et al. 2013).

The BS connects in the south to the central basin of the Baltic Sea, the Baltic Proper which has exchange with the ocean through the Danish straits. The northern Baltic Proper (nBP) has surface salinities of 6-7 PSU. In the middle of this connection is the island of Aland. East of $\AA$ Aland is the shallow Archipelago Sea with an average depth of $19 \mathrm{~m}$ and a sill depth of $18 \mathrm{~m}$ (Leppäranta and Myrberg 2009). On the western side is the Aland Sea ( with a maximum depth of $300 \mathrm{~m}$ and connected to the BS through channels of 150-m depth (Leppäranta and Myrberg 2009) with the sill at about $90 \mathrm{~m}$ (Hietala et al. 2007). The information on the actual sill depth between the $\AA \mathrm{S}$ and the 


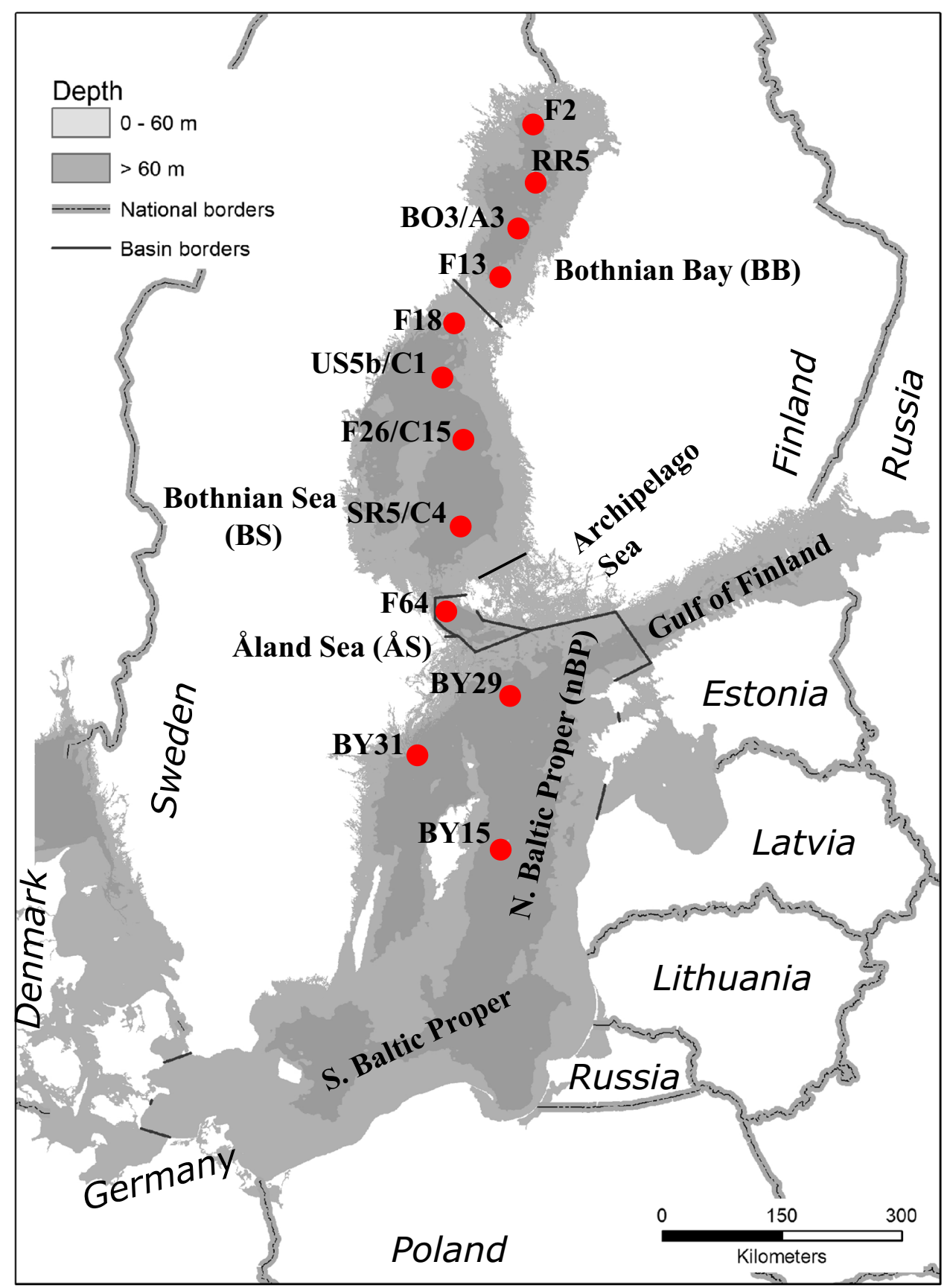

Fig. 1 Map of the Baltic Sea indicating the Bothnian Bay (BB), Bothnian Sea (BS), Åland Sea (ÅS), Archipelago Sea, and the northern Baltic Proper (nBP), and monitoring stations supplying data to the study. The Gulf of Bothnia (GoB) consists of the BB, BS, AS, and the Archipelago Sea

nBP differs between sources. Most sources give $45 \mathrm{~m}$, whereas Leppäranta and Myrberg (2009) citing (Fonselius and Malm 1996) gives $70 \mathrm{~m}$ as the correct sill depth. The residence time of the Baltic Proper is on the time scale of 30 years (Stigebrandt and Gustafsson 2003).

The Baltic Proper has experienced symptoms of eutrophication since the 1960s caused by the external loading of nutrients from a variety of sources including sewage and agricultural runoff (Larsson et al. 1985; Conley et al. 2009). In combination with permanent stratification and the limited exchange with the ocean, severe problems occur with hypoxia and anoxia affecting extensive areas of sediment. Periodic anoxia occurs naturally in the deeper parts but major inflows of oxygenated and saline oceanic water intermittently replace the anoxic bottom water. If inflows are sufficiently frequent the deep water is replaced 
with oxygenated water but infrequent inflows may instead strengthen the halocline causing stagnation and hypoxia. During the period since the late 1970s, the frequency and the intensity of such inflows have decreased drastically (Matthäus et al. 2008). Since 1983, only three substantial inflows of water with high salinity have occurred (1993, 1997, and 2003) with the 1997 inflow being of moderate volume.

Low oxygen concentrations during stagnation periods cause denitrification of oxidized nitrogen and accumulation of ammonium and phosphate, which can reach 35 and $7 \mu \mathrm{mol} \mathrm{L}{ }^{-1}$, respectively, in the deepest water. Phosphate from the deep water eventually causes elevated phosphate concentration in surface water, sometimes reaching $0.9 \mu \mathrm{mol} \mathrm{L}{ }^{-1}$. High phosphate concentrations are a prerequisite for blooms of nitrogen-fixing cyanobacteria which occur in the summer (Bianchi et al. 2000; Kahru et al. 2007; Raateoja et al. 2011). These sometimes become very extensive and can in themselves be a nuisance for holidaymakers and tourists, but they also fix considerable amounts of nitrogen and thereby substantially contribute to eutrophication. Nitrogen fixation has been estimated to contribute around 300000 tons of nitrogen annually (Larsson et al. 2001; Rolff et al. 2007) which is roughly a third of the total external nitrogen load on the Baltic Sea estimated by the Helsinki Commission (HELCOM 2009).

The phytoplankton production in the Baltic Proper has generally been found to be nitrogen limited (Granéli et al. 1990; Lignell et al. 2003; Tamminen and Andersen 2007; Danielsson et al. 2008; Walve and Larsson 2010). In particular, this applies to the spring bloom which is terminated when the inorganic nitrogen (DIN) supply is exhausted almost down to the halocline at 60-70-m depth, leaving some remaining phosphate (DIP) in the surface water above the developing thermocline. The nitrogen-fixing cyanobacterial summer blooms appear to be ultimately limited by the phosphate supply but also controlled by other factors such as temperature and the stability of the water mass (Kanoshina et al. 2003; Vahtera et al. 2005; Degerholm et al. 2006; Vahtera et al. 2010; Mohlin et al. 2012; Wasmund et al. 2012; Karlberg and Wulff 2013). The cyanobacteria also release considerable amounts of fixed nitrogen (Larsson et al. 2001; Rolff et al. 2007; Ploug et al. 2010). Limitation by both phosphorous and nitrogen can therefor occur which is difficult to study in the field or experimentally, since both nutrients occur at very low concentrations and are in rapid circulation. Both nitrogen and phosphorous may therefore potentially regulate production during summer, depending on the supply situation (Lignell et al. 2003; Vahtera et al. 2007; Walve and Larsson 2010; Raateoja et al. 2011).

There are very few studies of nutrient limitation in the GoB. The available information shows the $\mathrm{BB}$ to be phosphorous limited, but for the $\mathrm{BS}$, the information is more complex (Fonselius 1978; Granéli et al. 1990; Andersson et al. 1996; Tamminen and Andersen 2007; Lundberg et al. 2009). The BS has traditionally been considered to be mainly phosphorous limited; however, nutrient-enrichment experiments found phosphorous limitation in coastal areas, but nitrogen limitation in the open sea (Andersson et al. 1996). There is also a gradient of increasing nitrogen limitation from north to south further reflecting the freshwater influence (e.g., Tamminen and Andersen 2007). Danielsson et al. (2008) found no time trends in the ratio of DIN:DIP in open sea surface water (0-20 m) during any season of the year for the time period, 1970-2001. Before 1991, they found winter DIN:DIP ratios both above and below 16 without any trend, but these ratios were consistently below 16 from 1991 to 2001, whereas Andersson et al. found a ratio of $\sim 20$ and $\sim 10$ in the northern and southern BS, respectively, in 1991. In a coastal study on the north-eastern side of the BS, phosphorous limitation was found in spring and autumn but nitrogen limitation in summer (Tamminen and Andersen 2007). The BS therefore appears to be a shifting zone from phosphorous-to-nitrogen limitation in the freshwater gradients both from coastal to open sea and from north to south, and the limiting nutrient can also shift between seasons.

\section{MATERIALS AND METHODS}

Ideally, the nutrient limitation would be studied by the excess concentration of the nonlimiting nutrient in the production season. Regrettably, such data are not available for the BB and BS for recent years, and therefore the winter concentrations of DIN in relation to DIP were used to estimate the prerequisites for the spring bloom as discussed by, e.g., Granéli et al. (1990). A wide range of phytoplankton has remarkably constant composition of nitrogen relative phosphorous at the molar ratio 16:1. It is often referred to as the Redfield ratio (Redfield 1958), and it is useful to identify the limiting nutrient. Phytoplankton primary production is generally considered to be limited by nitrogen when molar DIN:DIP is below 16. Redfield ratios can, however, show variations between species and water bodies (Geider and La Roche 2002).

Using the DIN:DIP ratio in the water as an indicator of phytoplankton growth limitation has some disadvantages. Nutrient ratios are dimensionless and therefore give no quantitative information on nutrient availability. Particularly at low concentrations, ratios are also very sensitive to minute variations in the denominator (among those measurement errors), which can cause substantial change in the ratio. This can also give rise to statistical problems where ratios with 
low concentrations in the denominator may have strongly skewed distributions with sporadic extreme values causing high residual variation. In this study, we therefore use the difference between DIN and 16 times DIP measured in $\mu \mathrm{mol} \mathrm{L} \mathrm{L}^{-1}$ as a study variable. The variable will here be called $\Phi\left(\Phi=\left(\mathrm{NO}_{2}+\mathrm{NO}_{3}+\mathrm{NH}_{4}\right)-16 \times \mathrm{PO}_{4}\right) . \Phi$ is a difference and can be interpreted quantitatively as surplus or deficit of nitrogen and will have the same concentration unit as DIN and DIP. When $\Phi>0$, nitrogen occurs in excess and production is phosphorous limited; when $\Phi=0$, nutrients are balanced; and when $\Phi<0$, nitrogen availability limits the production. Accordingly a value of $\Phi=+1 \mu \mathrm{mol} \mathrm{L} \mathrm{L}^{-1}$ means excess of one micromole nitrogen, and $\Phi=-1$ will mean a corresponding deficit. Surplus and deficit of one micromole phosphorous will, however, correspond to $\Phi=-16$ and $\Phi=+16$, respectively.

Changes in basinwide proportions of nutrients are generally small and slow and are therefore difficult to detect. To increase the sensitivity in the analysis and avoid potential systematic differences between laboratories, only data from the annual winter cruise (late November or early December) of the Swedish Meteorological and Hydrological Institute (SMHI) were used. Ideally January-February values should be used, but sampling is then generally prevented by ice. Being in a high arctic area, the changes in DIN and DIP this late in the year are small, and the obtained values of $\Phi$ were good estimates of winter conditions, which was verified by analyses of monitoring data from years with sampling also in January-February. Data are publicly available in the database SHARK at the website of SMHI with quality information and analytic method descriptions. The software Statistica 6.1 was used for regression analysis.

In this study, we have analyzed data from three stations in the northern Baltic Proper, one station in the Aland Sea,

Table 1 Names of included stations from the Swedish national monitoring program. Geographic grouping in this study are indicated

\begin{tabular}{lll}
\hline Station name & Location & $\begin{array}{l}\text { Grouping } \\
\text { in this study }\end{array}$ \\
\hline BY15 & Central Baltic Proper & nBP \\
BY31 & Northern Baltic Proper & nBP \\
BY29 & Northern Baltic Proper & nBP \\
F64 & Aland Sea & AS \\
SR5/C4 & Southern Bothnian Sea & BS \\
F26/C15 & Central Bothnian Sea & BS \\
US5b/C1 & Northern Bothnian Sea & BS \\
F18 & Northern Bothnian Sea & BS \\
F13 & Southern Bothnian Bay & BB \\
BO3/A3 & Southern Bothnian Bay & BB \\
RR5 & Northern Bothnian Bay & BB \\
F2 & Northern Bothnian Bay & BB \\
\hline
\end{tabular}

and four stations each in the BS and the BB (Table 1; Fig. 1). Three stations in the nBP were included for comparative reasons and to investigate the potential causality of identified changes in the GoB. These stations were sampled at the same cruises as the stations in the GoB. The station BY15 is located in the central Baltic Proper but is included in the study, since it is highly representative for large-scale processes in the Baltic Proper and will be treated as belonging to the nBP. Station BY29 is the most representative of water from the Baltic Proper entering the ÅS and continuing on to the BS. Data exist from 1969 but is sometimes intermittent and do not always contain complete estimates of DIN prior to a standardized national program initiated in 1993. The long-term development of $\Phi$ in surface water was therefore calculated for each basin for all available years and depths above $20 \mathrm{~m}$ using the 12 stations in four basin wide groups (nBP, $\AA \mathrm{S}, \mathrm{BS}$, and BB; Table 1). In the long-term data, there is some variation in the timing of the cruise from week 45 to 51 with a predominance of earlier cruises during the 1980s.

A more detailed analysis was made by individual stations for the years 1990-2012 (for some stations only from 1993) to study recent changes and the consistency of trends between stations. Analytic precision has increased compared to the period before 1990 particularly for nitrogen, and the timing of the cruise has been more standardized. For the more detailed analysis, only data obtained after week 47 were analyzed, and only the depths of $0,5,10,15$, and $20 \mathrm{~m}$ were included to give an unbiased value of the surface water. In a few instances, samples from 6 and $8 \mathrm{~m}$ replaced the 5 and 10-m levels because of initial differences in the sampling programs.

\section{RESULTS}

A clear south-to-north gradient of $\Phi$ was found in the longterm analysis using all data available for surface water $(0-20 \mathrm{~m})$, going from strong nitrogen limitation in the $\mathrm{nBP}$ to strong phosphorous limitation in the BB (Fig. 2). The potential nutrient limitations differed distinctly between the basins BB, BS, and $\mathrm{nBP}$, whereas the $\AA \mathrm{S}$ resembled the nBP (Fig. 2). In the nBP, winter values of $\Phi$ were strongly negative, indicating a strong nitrogen limitation of the spring bloom (lower quartile $Q_{25}=-3.9$ and upper quartile $Q_{75}=-2.3 \mu \mathrm{mol} \mathrm{N} \mathrm{L}{ }^{-1}$ ). The $\AA$ A showed slightly less negative values of $\Phi \quad\left(Q_{25}=-2.4\right.$ and $Q_{75}=$ $-0.8 \mu \mathrm{mol} \mathrm{N} \mathrm{L}^{-1}$ ). In the BS, the pattern was different and centered around nutrient balance of $\Phi=0\left(Q_{25}=-0.8\right.$ and $Q_{75}=0.26 \mu \mathrm{mol} \mathrm{N} \mathrm{L}^{-1}$ ). The BB showed a clear surplus of nitrogen indicated by strongly positive values of $\Phi\left(Q_{25}=4.9\right.$ and $\left.Q_{75}=5.4 \mu \mathrm{mol} \mathrm{N} \mathrm{L}{ }^{-1}\right)$. In the nBP, $\AA$, and to some extent in the BS, $\Phi$ showed no clear temporal 


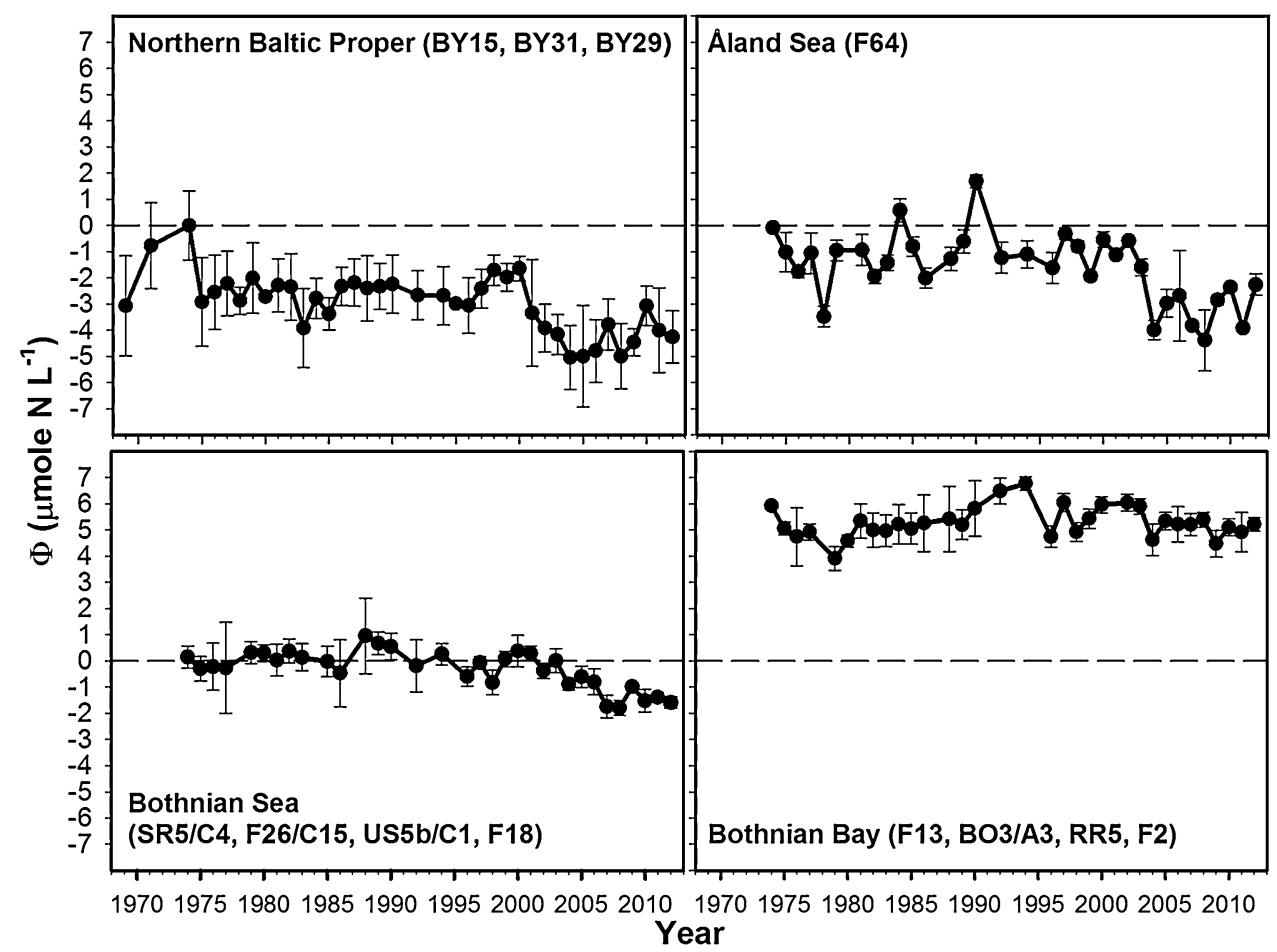

Fig. 2 Long-term basin estimates of $\Phi$ (mean and SD) in winter surface water (November-December, 0-20 m) in the basins nBP, Ås, BS, and BB using data from the winter cruise of the SMHI. Balanced nutrients $(\Phi=0)$ indicated

trend from 1969 to 2000 but an abrupt development toward stronger nitrogen limitation after 2000. In approximate terms, $\Phi$ in the nBP declined from -3 to $-5 \mu \mathrm{mol} \mathrm{N} \mathrm{L} \mathrm{L}^{-1}$ and in the $\AA \mathrm{S}$ from -1 to $-4 \mu \mathrm{mol} \mathrm{N} \mathrm{L}{ }^{-1}$, whereas $\Phi$ in the BS changed from values around 0 to $-1.5 \mu \mathrm{mol} \mathrm{N} \mathrm{L}{ }^{-1}$. The changes were the most pronounced in the nBP and $\AA \mathrm{S}$ with a weaker trend in the BS, whereas no long-term temporal trend was evident in the BB.

The general trends found at the basin scale could be recognized at the individual stations for the period 1990-2011 and were consistent for stations located in the same basin (Fig. 3). The change in $\Phi$ toward more pronounced nitrogen limitation around year 2000 could be identified at all stations in the $\mathrm{nBP}$ and $\AA \mathrm{S}$. Even if regressions were significant, the regression explained variation was low (low $R$-square), because of a marked nonlinear shift around the year 2000. In the BS, the shift was gradual and showed a continuous decline without marked shift, and the linear time trends were highly significant ( $p<0.003$, statistics in Fig. 3). The intercepts (243, 243,215 , and $\left.178 \mu \mathrm{mol} \mathrm{N} \mathrm{L}{ }^{-1}\right)$ and slopes $(-0.12,-0.12$, $-0.11,-0.09 \mu \mathrm{mol} \mathrm{N} \mathrm{L}{ }^{-1} \mathrm{yr}^{-1}$ ) found in the BS were very similar for stations SR5/C4, F26/C15, US5b/C1, and F18, respectively. Slopes became less steep, and intercepts decreased going from south to north as did R-squares $(0.85$, $0.71,0.57$, and 0.44 , for stations as above). In the $\mathrm{BB}$, there were no strong temporal trends and low values of $R$-square. Yearly averages were used in the regressions to avoid unintentional weighting of years since there were sporadic occurrences of missing data. Results were, however, almost identical, if all data were used instead of yearly averages.

February values are generally considered as being the most representative for winter season's inorganic nutrients. In this study, data obtained from the November to December cruise were used also for the nBP and Ås with the exception of water column description as shown in Fig. 4. In the BB and BS, the winter has progressed considerably further during November-December than in the nBP. To ensure that there were no considerable differences in $\Phi$ values calculated from January to February, in relation to November-December values, a time series of monthly values from the years 1990 to 1999 were investigated. Such data were obtainable for stations BY31, US5b/C1, and station F9/A13 in the southern BB (not indicated in Fig. 1).

At station BY31, $\Phi$ values reached a minimum of $\sim-3.8$ in January and a maximum in August of $\sim-0.5$ (Fig. 5). The January $\Phi$ values were $0.6-1.4 \mu \mathrm{mol} \mathrm{N} \mathrm{L}{ }^{-1}$ lower than those during November-December. This is a substantial difference in relation to the difference between the minimum and the maximum. Potential nitrogen limitations of the spring bloom are thus underestimated in the nBP and $\AA \mathrm{S}$ when using November-December data 


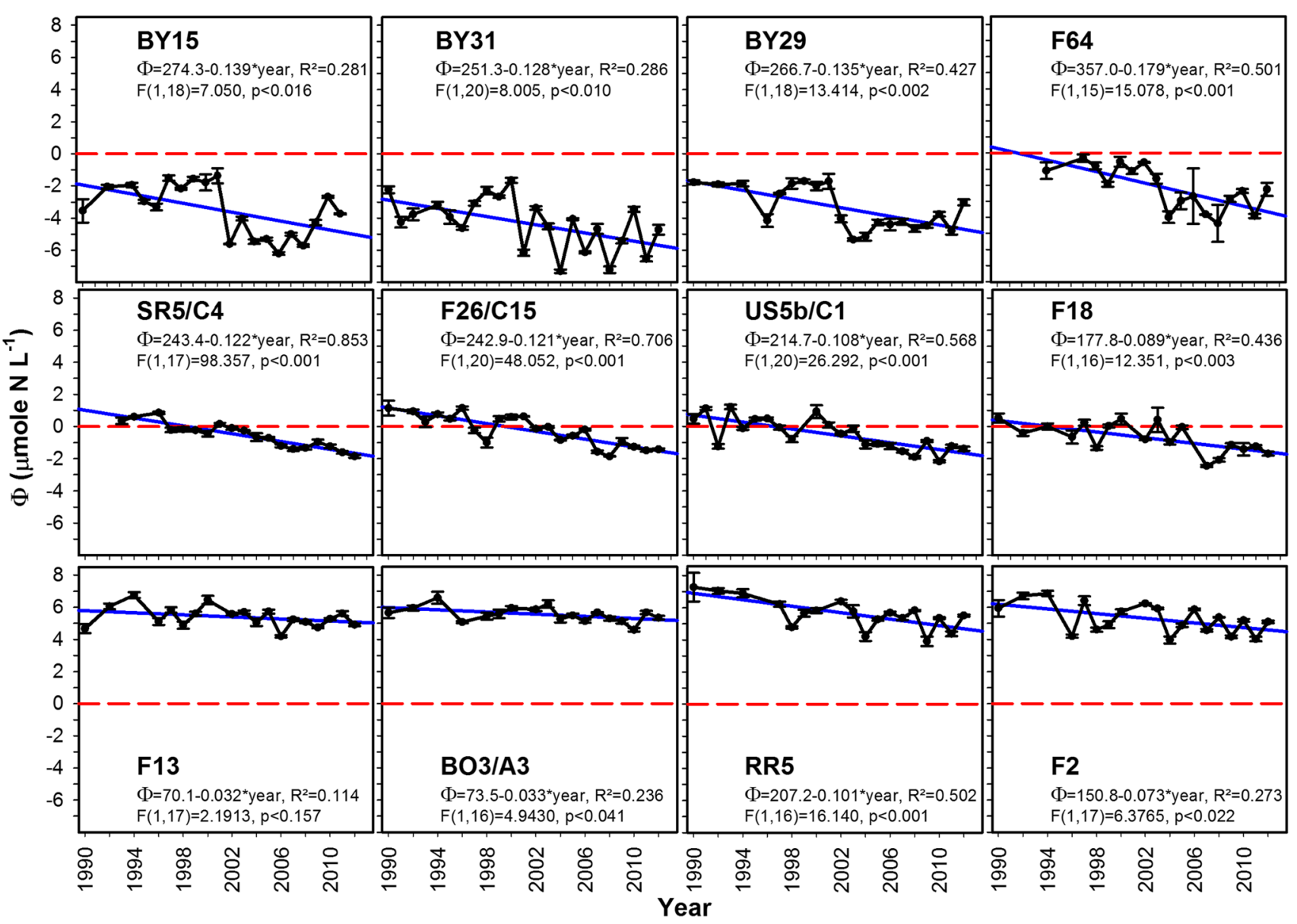

Fig. 3 The development of $\Phi$ at individual stations (mean and SD) in winter surface water (0, 5, 10, 15, and 20 m) during winter from 1990 (F64 and SR5/C4 from 1993) to 2012. Upper nBP and Ås, middle BS, lower BB. Balanced nutrients $(\Phi=0)$ indicated

compared with January-February. The difference between the $\mathrm{nBP}$ and the other basins is thus in reality greater than that indicated in this study. At the stations in the BS and $\mathrm{BB}$, the differences in the values of $\Phi$ during JanuaryFebruary and November-December were small, and the latter are likely to be representative of winter conditions. In the BS, the November-December data represent a minor overestimate $\left.(\sim 0.3 \mu \mathrm{mol} \mathrm{N} \mathrm{L})^{-1}\right)$ of $\Phi$ compared to $\mathrm{Fe}$ bruary data, but only $\sim 0.15 \mu \mathrm{mol} \mathrm{N} \mathrm{L}{ }^{-1}$ compared to January values. The February data were only available for 3 years in the time series.

\section{DISCUSSION}

\section{Causality behind the shift to nitrogen limitation in the Bothnian Sea}

The area of seafloor in the Baltic Proper covered by anoxic water is now greater than that previously recorded (Hansson et al. 2013; Carstensen et al. 2014). Around $15 \%$ of the seafloor is anoxic, and $28 \%$ are hypoxic. The volume of hypoxic- and phosphate-rich water in the $\mathrm{nBP}$ has its upper limit at about 50-60-m depth, just above the halocline (Fig. 4). Cyclonic and estuarine circulations cause a southgoing surface stream through the $\AA \mathrm{S}$ and a compensating north-going stream of above halocline water from the $\mathrm{nBP}$ that forms deep waters in the $\AA \mathrm{S}$ and BS. If the thresholds to the Åland Sea are indeed deeper than $45 \mathrm{~m}$ hypoxic, phosphate-rich water close to the halocline can periodically also enter the $\AA \mathrm{S}$ and contribute to the water overlaying sediments in the deeper parts of the BS. The corresponding salinity values of water found in the deepest parts of $\AA \mathrm{S}$ (F64) during the period (1990-2012) were found at between 50- and 60-m depths at BY29 in the nBP, showing passage of water from greater depths than $45 \mathrm{~m}$ in the nBP.

Oceanographic key variables in the nBP and the central BS showed a clearly parallel development (Fig. 4), with increasing deep water salinity, decreasing oxygen concentration, and increasing phosphate concentration. After the turn of the twenty-first century, the phosphate concentration increased dramatically below the halocline in the 

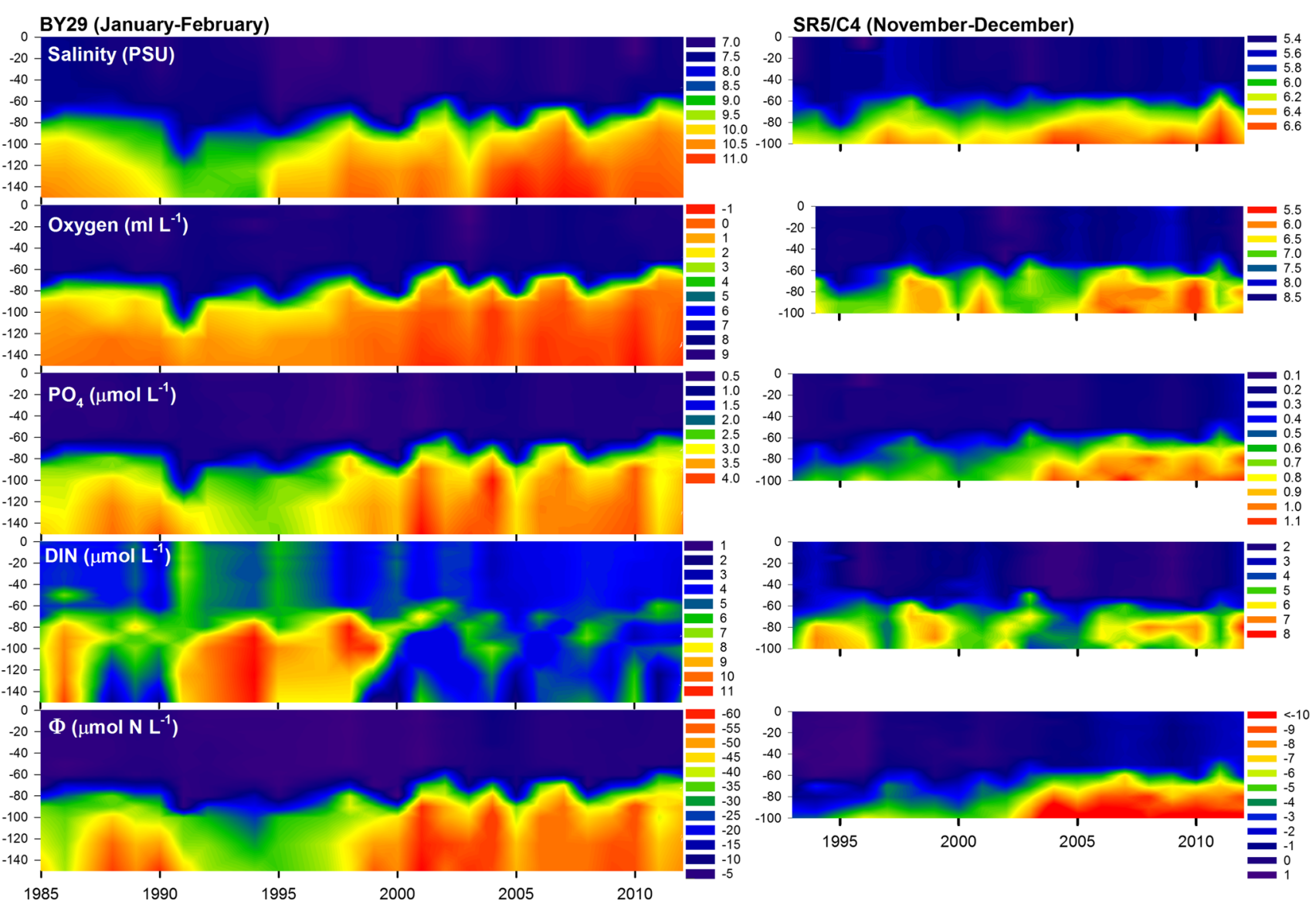

Fig. 4 Salinity (PSU), oxygen concentration ( $\mathrm{ml} \mathrm{L}^{-1}$, oxygen required to oxidize $\mathrm{H}_{2} \mathrm{~S}$ as negative oxygen concentration), phosphate concentration $\left(\mu \mathrm{mol} \mathrm{L}^{-1}\right)$, DIN $\left(\mu \mathrm{mol} \mathrm{L}^{-1}\right)$, and $\Phi\left(\mu \mathrm{mol} \mathrm{N} \mathrm{L}{ }^{-1}\right)$ at stations BY29 (nBP) and SR5/C4 (BS). For station SR5/C4, NovemberDecember data were used, but for BY29, January-February data were used because of better data coverage and better representation of winter concentrations. Note that time and color scales differ between stations and that they have been cut to exclude extremes. The upper and lower levels of the color scales should therefore be interpreted as "or greater" and "or less" respectively

nBP because of anoxic or hypoxic conditions with a corresponding, but less consistent, increase in the surface water. Very high phosphate levels (up to $\sim 3 \mu \mathrm{mol} \mathrm{P} \mathrm{L}^{-1}$ ) were found close to the halocline at station BY29 in the nBP (Fig. 4). The trends in DIN are less clear, but the hypoxic conditions since the 1993 inflow caused nitrate to be denitrified in the deep water (e.g., Conley et al. 2009) followed by ammonium accumulation. The release of phosphate was, however, much more pronounced as can be seen from the progressively negative values of $\Phi$ at BY29 (Fig. 4).

From 1994 to 2012, there were no strong trends in external loads to the BS with uncertain estimates suggesting a somewhat greater relative reduction of phosphorous load in relation to nitrogen load on a weight basis (HELCOM 2013). The trends in the water column of the nBP, however, corresponded with damped equivalents in the BS (Fig. 4). The hypoxia and elevated concentrations of phosphate found at 50-60-m depth in the nBP are thus likely to be the main cause of the decreasing oxygen concentration and increasing phosphate concentration in the deep water of the BS (Fig. 4). The trend toward more nitrogen-limited conditions in the BS is likely to be driven by inflow of phosphate-rich water from the nBP, forming deep water in the BS since there is no consistent trend in DIN concentration in the water column (Fig. 6). For all the key variables, changes in the deep water precede the corresponding changes in surface water. Generally speaking, these are increasing deep water salinity, decreasing oxygen concentration below the halocline, increasing phosphate concentration, and variable trends in DIN. All trends were most pronounced below the halocline.

\section{Potential consequences in the Bothnian Sea}

The BS has been considered as an area that can show both $\mathrm{P}$ and $\mathrm{N}$ limitations shifting between seasons and in a north-to-south and coastal-to-open sea gradient (Fonselius 1978; Tamminen and Andersen 2007). A reasonable assumption is that increased phosphorous load from the $\mathrm{nBP}$ 


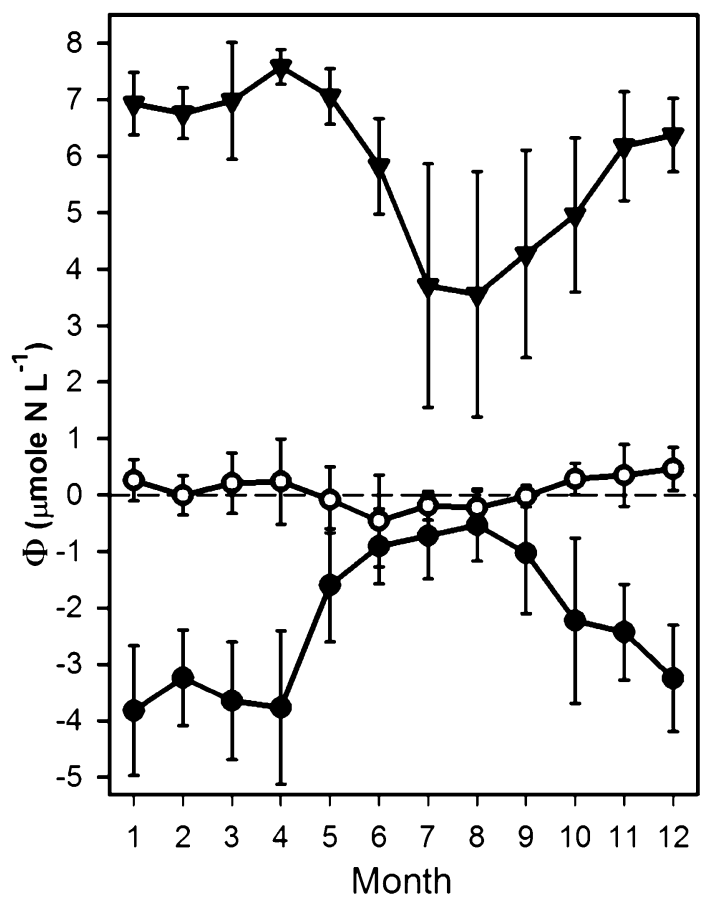

Fig. 5 Monthly means of $\Phi$ (SD indicated) in surface water (0-20 m) at stations BY31 (nBP), SR5/C4 (BS), and F9/A13 (southern BB, not indicated in Fig. 1) for the years 1993-1999 when data where obtained for most years at a monthly basis

would cause increased production. An extensive review found summertime chlorophyll- $a$ in the BS to increase threefold from the late 1970s to the end of the 1990s $(\sim 1.1$ to $\left.\sim 3.2 \mu \mathrm{g} \mathrm{L}^{-1}\right)$, and then decrease again to $\sim 2.4 \mu \mathrm{g} \mathrm{L}^{-1}$ during the period 2004-2006 (Fleming-Lehtinen et al. 2008). In a major review by the Helsinki Commission, chlorophyll- $a$ was found to increase, and Secchi depth was shown to decrease for the period 1975-2007 (HELCOM 2009). National Swedish monitoring in the northern part of the open BS has shown a decreasing trend from around $2 \mu \mathrm{g} \mathrm{L}^{-1}$ in the early 1990 s to values slightly above $1 \mu \mathrm{g} \mathrm{L}^{-1}$ during 2000-2004, and then a change back to values around $2 \mu \mathrm{g} \mathrm{L}^{-1}$ with considerable inter-annual variation and no clear time trends (Höglander et al. 2012). In a multivariate study of eutrophication indicators, coastal eutrophication was not found to be strong in the BS (Lundberg et al. 2009). For the GoB, the same study, however, found a north-to-south gradient of increasing eutrophication and an increasing trend in time.

As discussed above, there is no strong general trend for chlorophyll- $a$ in the BS; most studies, however, suggest higher concentrations of chlorophyll- $a$ during the last 10 years (Fleming-Lehtinen et al. 2008; HELCOM 2009; Lundberg et al. 2009; Höglander et al. 2012). Decreasing oxygen concentration in the deep water of the BS may suggest an increased production and sedimentation, causing oxygen consumption in the sediment. It is, however, unknown how much of the decrease in deep water oxygen concentration can be attributed to transport of oxygen-depleted deep water from the nBP and how much can be explained by local oxygen consumption in the sediment or deep water. In the deepest $30 \mathrm{~m}$ of water at station SR5, the oxygen concentration is slightly lower, and the phosphate concentration is slightly higher than those at 50-m depth in the nBP (BY29), suggesting also some local oxygen consumption and phosphate release in the BS.

The shift in nutrient limitation may lead to higher productivity in the BS. It is, however, essential to consider that the Redfield ratio is a general relation between nutrients in oceanic phytoplankton. The ratio has natural variations (Geider and La Roche 2002) and may thus have a value different from 16 in the BS. A study in the nBP found the molar N:P-ratio in seston to increase from values slightly below 16 in spring to 23 in late August (when diazotrophic cyanobacteria are frequent), and thereafter it decreased (Walve and Larsson 2010). The value 0 of $\Phi$ should therefore not be strictly interpreted as a distinct limit, and the movement toward more negative values of $\Phi$ is rather to be seen as a progressive shift toward increasing nitrogen limitation of the spring bloom. The values of $\Phi \sim-2$ found around year 2010 in the BS are, however, similar to those found around the turn of the century in the $\mathrm{nBP}$, where the spring bloom is strongly nitrogen limited (Figs. 2, 3). The nitrogen-fixing cyanobacteria Aphanizomenon sp. has also been found to increase in the BS (Jaanus et al. 2011; Höglander et al. 2012) which generally is an indication of nitrogen-limited production conditions.

\section{Should the change cause immediate concern?}

In the present situation, the results are not dramatic but should be closely monitored to evaluate if the winter pool of nutrients in the BS increases substantially, if chlorophyll- $a$ will be found to increase and if the deep water oxygen levels continue to drop. During the 1990s, nutrients were measured monthly in the national Swedish marine monitoring program at station US5b/C1 in the northern BS. Analysis of these data showed that the DIN pool was almost exhausted down to approximately $50-\mathrm{m}$ depth by the spring bloom which hereby consumes $\sim 4 \mu \mathrm{mol} \mathrm{N} \mathrm{L}{ }^{-1}$ $\left(56 \mu \mathrm{g} \mathrm{N} \mathrm{L}^{-1}\right)$. The volume of the BS down to 50-m depth is $\sim 2770 \mathrm{~km}^{3}$ from which can be calculated an approximate consumption of 155000 tons of DIN by the spring bloom. The annual load of total nitrogen to the BS by HELCOM is estimated to be $\sim 50000$ tons $\mathrm{N} \mathrm{yr}^{-1}$ of which roughly half the amount $\left(\sim 25000\right.$ tons $\left.\mathrm{N} \mathrm{yr}^{-1}\right)$ is considered as anthropogenic and the rest as natural background load from mainly forestland (HELCOM 2011). 

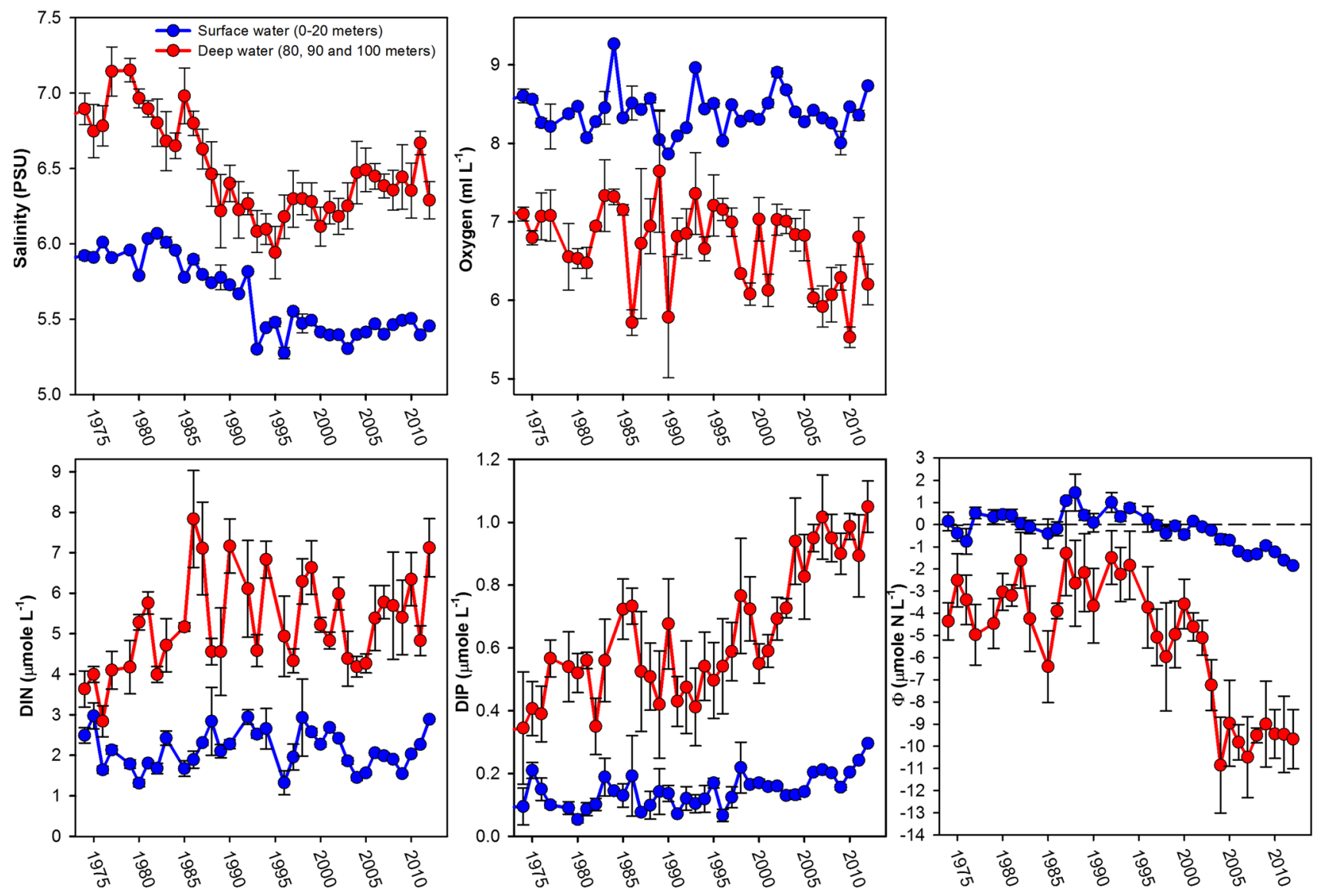

Fig. 6 November-December salinity, oxygen, phosphate, DIN, and $\Phi$ values in surface water $(0,5,10,15$, and $20 \mathrm{~m})$ and deep water $(80,90$, and $100 \mathrm{~m}$ ) at station SR5/C4 (mean and SD). Changes in the deep water precede those of the surface water

There is no basinwide estimate of inorganic load of nitrogen, but slightly less than a third is inorganic in the Swedish estimates of riverine load. The direct emissions from municipal wastewater treatment plants into the BS is estimated to be $\sim 2100$ tons $\mathrm{N} \mathrm{yr}^{-1}$ (HELCOM 2011). In relation to the nitrogen consumed by the spring bloom, it is a comparatively small amount. However, nitrogen in emissions from MWWT generally consists almost exclusively of inorganic nitrogen. The MWWTs can therefore not be considered a major source of total nitrogen but may locally be an important source to inorganic load.

The increasing amount of phosphate is likely to cause some increase in spring bloom production in the BS. If increased sedimentation does not cause any significant decline in deep-water oxygen concentration and it remains sufficiently high to stabilize phosphate by oxidized iron, then the change can be seen as a mechanism by which the Baltic Proper can export excess phosphate to the BS, which is considered as only mildly eutrophic. The decreasing oxygen levels of the BS would in this perspective be caused mainly by transport of near halocline water from the $\mathrm{nBP}$ and not by increased local oxygen consumption.
Increased production and nitrogen limitation would further decrease the relatively small transport of nitrogen to the nitrogen sensitive Baltic Proper. This net transport has been estimated to be 31000 tons $\mathrm{N} \mathrm{yr}^{-1}$ (Savchuk 2005) which is $\sim 5 \%$ of the external load on the Baltic Proper of $\sim 350000$ tons $\mathrm{N} \mathrm{yr}^{-1}$ (excluding the Gulfs of Finland and Riga) (HELCOM 2012) plus the internal load by nitrogen fixation of $\sim 300000$ tons $\mathrm{N} \mathrm{yr}^{-1}$ (Larsson et al. 2001; Rolff et al. 2007). If on the contrary local oxygen consumption in the deep water of the BS is significant, then the BS may come to suffer from similar but less-severe problems as the Baltic Proper. The short residence time of the water, weaker halocline, more efficient winter circulation, and lower production of the BS compared with the Baltic Proper are, however, likely to mitigate severe oxygen conditions in the deep water (Raateoja 2013). It is, however, not well known how the release of phosphate from the sediment is affected by moderate decreases in oxygen concentration in the deep water.

The clear similarity in the temporal development of all variables between station SR5 and BY29 strongly suggests that the nBP drives the observed changes. To what extent 
internal processes contribute to the development cannot be evaluated presently. A situation may be reached where also the nitrogen loads on the BS must be considered if the development toward a nitrogen limited production continues and potentially is reinforced by internal processes.

\section{CONCLUSIONS}

The study showed a shift toward more nitrogen-limited conditions for the spring bloom in the BS during the last 20 years. The change in DIN relative DIP occurs first in the deep water and then progresses to the surface water suggesting that it is caused by inflow of phosphate-rich and oxygen-depleted water from depths near the halocline in the nBP and not by changes in external input. The change can potentially cause some increased production in the BS and potentially increase cyanobacterial blooms. There does not appear to be any immediate concern in the short-term perspective for the state of the BS, but a progression of the processes could lead to a more eutrophic state of the BS.

Acknowledgments This study was financed by the Swedish Environmental Protection Agency. The authors also wish to thank Bo Gustafsson, Christoph Humborg, and Oleg Savchuk for valuable discussions; Erik Smedberg for assistance with graphics; Claes Bernes for permission to use published graphic material; and Ulf Larsson for valuable comments on the manuscript.

Open Access This article is distributed under the terms of the Creative Commons Attribution 4.0 International License (http:// creativecommons.org/licenses/by/4.0/), which permits unrestricted use, distribution, and reproduction in any medium, provided you give appropriate credit to the original author(s) and the source, provide a link to the Creative Commons license, and indicate if changes were made.

\section{REFERENCES}

Andersson, A., S. Hajdu, P. Haecky, J. Kuparinen, and J. Wikner. 1996. Succession and growth limitation of phytoplankton in the Gulf of Bothnia (Baltic Sea). Marine Biology 126: 791-801.

Bianchi, T.S., E. Engelhaupt, P. Westman, T. Andren, C. Rolff, and R. Elmgren. 2000. Cyanobacterial blooms in the Baltic Sea: Natural or human-induced? Limnology and Oceanography 45: 716-726.

Carstensen, J., J.H. Andersen, B.G. Gustafsson, and D.J. Conley. 2014. Deoxygenation of the Baltic Sea during the last century. Proceedings of the National Academy of Sciences 111: 5628-5633.

Conley, D.J., S. Björck, E. Bonsdorff, J. Carstensen, G. Destouni, B.G. Gustafsson, S. Hietanen, M. Kortekaas, et al. 2009. Hypoxia-related processes in the Baltic Sea. Environmental Science and Technology 43: 3412-3420.

Danielsson, A., L. Papush, and L. Rahm. 2008. Alterations in nutrient limitations-Scenarios of a changing Baltic Sea. Journal of Marine Systems 73: 263-283.
Degerholm, J., K. Gundersen, B. Bergman, and E. Söderbäck. 2006. Phosphorus-limited growth dynamics in two Baltic Sea cyanobacteria, Nodularia sp. and Aphanizomenon sp. FEMS Microbiology Ecology 58: 323-332.

Fleming-Lehtinen, V., M. Laamanen, H. Kuosa, H. Haahti, and R. Olsonen. 2008. Long-term development of inorganic nutrients and chlorophyll alpha in the open northern Baltic sea. AMBIO 37: 86-92.

Fonselius, S.H. 1978. On nutrients and their role as production limiting factors in the Baltic. Acta Hydrochimica et Hydrobiologica 6: 329-339.

Fonselius, S.H., and A. Malm. 1996. Västerhavets och Östersjöns oceanografi. Norrköping, Swedish Meteorological and Hydrological Institute (SMHI), Sweden (in Swedish).

Geider, R.J., and J. La Roche. 2002. Redfield revisited: Variability of $\mathrm{C}: \mathrm{N}: \mathrm{P}$ in marine microalgae and its biochemical basis. European Journal of Phycology 37: 1-17.

Granéli, E., K. Wallström, U. Larsson, W. Granéli, and R. Elmgren. 1990. Nutrient limitation of primary production in the Baltic Sea area. AMBIO 19: 142-151.

Hansson, M., L. Andersson, P. Axe, and J. Szaron. 2013. Oxygen survey in the Baltic Sea 2012-Extent of anoxia and hypoxia, 1960-2012. Swedish Meteorological and Hydrological Institute (SMHI), Report RO 46.

HELCOM. 2009. Eutrophication in the Baltic Sea-An integrated thematic assessment of the effects of nutrient enrichment and eutrophication in the Baltic Sea region. Baltic Sea Environment Proceedings No. 115B.

HELCOM. 2011. Fifth Baltic Sea pollution load compilation (PLC5). Baltic Sea Environment Proceedings No. 128.

HELCOM. 2012. The fifth Baltic Sea pollution load compilation (PLC-5)-An executive summary. Baltic Sea Environment Proceedings No. 128A.

HELCOM. 2013. Review of the fifth Baltic Sea pollution load compilation for the 2013 HELCOM ministerial meeting. Baltic Sea Environment Proceedings No. 141.

Hietala, R., P. Lundberg, and J.A.U. Nilsson. 2007. A note on the deep-water inflow to the Bothnian Sea. Journal of Marine Systems 68: 255-264.

Höglander, H., S. Hajdu, A.-T. Skjevik, A. Andersson, and C. Karlsson. 2012. Pelagial biologi/växtplankton. HAVET 2012, Sweden, pp. 48-49 (in Swedish). Retrieved from http://www. havsmiljoinstitutet.se/publikationer/havet/2012/.

Jaanus, A., A. Andersson, I. Olenina, K. Toming, and K. Kaljurand. 2011. Changes in phytoplankton communities along a northsouth gradient in the Baltic Sea between 1990 and 2008. Boreal Environment Research 16: 191-208.

Kahru, M., O.P. Savchuk, and R. Elmgren. 2007. Satellite measurements of cyanobacterial bloom frequency in the Baltic Sea: Interannual and spatial variability. Marine Ecology Progress Series 343: 15-23.

Kanoshina, I., U. Lips, and J.M. Leppänen. 2003. The influence of weather conditions (temperature and wind) on cyanobacterial bloom development in the Gulf of Finland (Baltic Sea). Harmful Algae 2: 29-41.

Karlberg, M., and A. Wulff. 2013. Impact of temperature and species interaction on filamentous cyanobacteria may be more important than salinity and increased $\mathrm{pCO}_{2}$ levels. Marine Biology 160: 2063-2072.

Larsson, U., R. Elmgren, and F. Wulff. 1985. Eutrophication and the Baltic Sea-Causes and consequences. AMBIO 14: 9-14.

Larsson, U., S. Hajdu, J. Walve, and R. Elmgren. 2001. Baltic Sea nitrogen fixation estimated from the summer increase in upper mixed layer total nitrogen. Limnology and Oceanography 46: 811-820. 
Leppäranta, M., and K. Myrberg. 2009. Physical oceanography of the Baltic Sea. Berlin: Springer-Verlag.

Lignell, R., J. Seppälä, P. Kuuppo, T. Tamminen, T. Andersen, and I. Gismervik. 2003. Beyond bulk properties: Responses of coastal summer plankton communities to nutrient enrichment in the northern Baltic Sea. Limnology and Oceanography 48: 189-209.

Lundberg, C., B.M. Jakobsson, and E. Bonsdorff. 2009. The spreading of eutrophication in the eastern coast of the Gulf of Bothnia, northern Baltic Sea-An analysis in time and space. Estuarine, Coastal and Shelf Science 82: 152-160.

Matthäus, W., D. Nehring, R. Feistel, G. Nausch, V. Mohrholz, and H.U. Lass. 2008. The inflow of highly saline water into the Baltic Sea. In State and evolution of the Baltic Sea, 1952-2005: A detailed 50-year survey of meteorology and climate, physics, chemistry, biology, and marine environment, ed. R. Feistel, G. Naush, and N. Wasmund, 265-309. Hoboken, NJ: WileyInterscience.

Mohlin, M., M.Y. Roleda, B. Pattanaik, S.J. Tenne, and A. Wulff. 2012. Interspecific resource competition-combined effects of radiation and nutrient limitation on two diazotrophic filamentous cyanobacteria. Microbial Ecology 63: 736-750.

Ploug, H., N. Musat, B. Adam, C.L. Moraru, G. Lavik, T. Vagner, B. Bergman, and M.M.M. Kuypers. 2010. Carbon and nitrogen fluxes associated with the cyanobacterium Aphanizomenon sp. in the Baltic Sea. ISME Journal 4: 1215-1223.

Raateoja, M. 2013. Deep-water oxygen conditions in the Bothnian Sea. Boreal Environment Research 18: 235-249.

Raateoja, M., H. Kuosa, and S. Hällfors. 2011. Fate of excess phosphorus in the Baltic Sea: A real driving force for cyanobacterial blooms? Journal of Sea Research 65: 315-321.

Redfield, A.C. 1958. The biological control of chemical factors in the environment. American Scientist 46: 205-221.

Rolff, C., L. Almesjö, and R. Elmgren. 2007. Nitrogen fixation and abundance of the diazotrophic cyanobacterium Aphanizomenon sp. in the Baltic Proper. Marine Ecology Progress Series 332: $107-118$

Savchuk, O.P. 2005. Resolving the Baltic Sea into seven subbasins: N and P budgets for 1991-1999. Journal of Marine Systems 56: $1-15$.

Stigebrandt, A., and B.G. Gustafsson. 2003. Response of the Baltic Sea to climate change-Theory and observations. Journal of Sea Research 49: 243-256.

Tamminen, T., and T. Andersen. 2007. Seasonal phytoplankton nutrient limitation patterns as revealed by bioassays over Baltic
Sea gradients of salinity and eutrophication. Marine Ecology Progress Series 340: 121-138.

Vahtera, E., R. Autio, H. Kaartokallio, and M. Laamanen. 2010. Phosphate addition to phosphorus-deficient Baltic Sea plankton communities benefits nitrogen-fixing Cyanobacteria. Aquatic Microbial Ecology 60: 43-57.

Vahtera, E., D.J. Conley, B.G. Gustafsson, H. Kuosa, H. Pitkänen, O.P. Savchuk, T. Tamminen, M. Viitasalo, et al. 2007. Internal ecosystem feedbacks enhance nitrogen-fixing cyanobacteria blooms and complicate management in the Baltic Sea. AMBIO 36: 186-194.

Vahtera, E., J. Laanemets, J. Pavelson, M. Huttunen, and K. Kononen. 2005. Effect of upwelling on the pelagic environment and bloom-forming cyanobacteria in the western Gulf of Finland, Baltic Sea. Journal of Marine Systems 58: 67-82.

Walve, J., and U. Larsson. 2010. Seasonal changes in Baltic Sea seston stoichiometry: The influence of diazotrophic cyanobacteria. Marine Ecology Progress Series 407: 13-25.

Wasmund, N., G. Nausch, and M. Voss. 2012. Upwelling events may cause cyanobacteria blooms in the Baltic Sea. Journal of Marine Systems 90: 67-76.

Yi, P., G. Possnert, A. Aldahan, X.L. Hou, A.C. Bryhn, and P. He. 2013. ${ }^{129}$ I in the Baltic Proper and Bothnian Sea: Application for estimation of water exchange and environmental impact. Journal of Environmental Radioactivity 120: 64-72.

\section{AUTHOR BIOGRAPHIES}

Carl Rolff $(\square)$ is a senior scientist working mainly with eutrophication research. His previous research includes stable isotope research in plankton food webs and food-chain transfer of persistent organic environmental contaminants.

Address: Stockholm University Baltic Sea Centre, 10691 Stockholm, Sweden.

e-mail: carl.rolff@su.se

Tina Elfwing is a senior scientist working mainly with eutrophication research. She has previously worked with ecotoxicological and genetic research and is also the director of the Stockholm University Baltic Sea Centre.

Address: Stockholm University Baltic Sea Centre, 10691 Stockholm, Sweden.

e-mail: tina.elfwing@su.se 